\title{
O CONSTITUCIONALISMO PÓS SEGUNDA GUERRA MUNDIAL E O \\ CRESCENTE ATIVISMO JUDICIAL NO BRASIL: UMA ANÁLISE DA EVOLUÇÃO DO PAPEL DO PODER JUDICIÁRIO PARA A EFETIVAÇÃO DAS CONSTITUIÇÕES SUBSTANCIALISTAS
}

\section{POST 2ND WORLD WAR CONSTITUTIONALISM AND JUDICIAL ACTIVISM IN BRASIL: AN APPROACH OF THE EVOLUTION OF JUDICIARY ROLE TO EFFECTIVE SUBSTANTIAL CONSTITUTIONS}

1Tatiana Mareto Silva

\section{RESUMO}

O substancialismo das constituições tornou-se fenômeno histórico após o período da $2^{\mathrm{a}}$ Guerra Mundial, significando a positivação de direitos fundamentais nas cartas constitucionais que, consequentemente, levou ao aumento das atribuições judiciais constitucionais. O presente ensaio aborda a evolução do constitucionalismo até o neoconstitucionalismo, com foco nas Constituições Brasileiras de 1946 e 1988 e a atuação do Supremo Tribunal Federal para a efetivação dos direitos fundamentais previstos na Constituição de 1988, com objetivo principal de compreender por que a Corte Constitucional pátria vem dominando o cenário político não obstante a atipicidade desse movimento.

Palavras-chave: Neoconstitucionalismo, Substancialismo constitucional, Ativismo judicial

\begin{abstract}
Substantialism of constitutions became a historical phenomenon after 2nd World War, meaning the insertion of fundamental rights in constitutional charts what, consequentially, developed to the growth of constitutional judicial powers. This essay approaches the evolution of constitutionalism to neoconstitutionalism, focusing Brazilian Constitutions of 1946 and 1988 and Supremo Tribunal Federal's role to effectiveness of fundamental rights written in 1988 Constitution, aiming to understand why the Constitutional Court is dominating the political scenario despite of the atypicity of this behavior.
\end{abstract}

Keywords: Neoconstitutionalism, Constitutional substantialism, Judicial activism

\footnotetext{
1 Doutoranda em Direitos e Garantias Fundamentais da Faculdades Integradas de Vitória. Professora da Faculdade de Direito de Cachoeiro de Itapemirim. Faculdade de Direito de Cachoeiro de Itapemirim - FDCI, Espírito Santo. Brasil - E-mail: tmareto@gmail.com
} 

da Evolução do Papel do Poder Judiciário para a Efetivação das Constituições Substancialistas

\section{INTRODUÇÃO}

Em 1945 encerrou-se a $2^{\text {a }}$ Guerra Mundial com a vitória dos países democráticos, encabeçados então pelos Estados Unidos da América, o que teve reflexos diretos na política e no constitucionalismo Brasileiros. O país vinha governado de forma autoritária por Getúlio Vargas, que apoiou, no início da Guerra, as nações derrotadas e seus modelos de Estado. Com a vitória dos Aliados, as pressões sobre o governo ditatorial de Getúlio se intensificaram, uma vez a constatação de que não seria mais possível tolerar o autoritarismo no Brasil.

Não foi apenas o Brasil a sofrer os efeitos dessa onda de liberalismo e democracia. Muitos países ocidentais modificaram suas constituições em razão do pós-guerra - na América Latina, em 1946 Brasil, Equador, Haiti e Panamá promulgaram novas constituições, seguidos por República Dominicana, Peru e Venezuela em 1947 e Nicarágua e México em 1948. Sem contar os demais países da Europa que também tiveram seus regimes constitucionais renovados, como França em 1946, Itália em 1947, Bulgária em 1948 e Alemanha em 1949, apenas a título exemplificativo.

Essas constituições, no entanto, tinham papel quase que figurativo e pouco articulado, impondo uma distância significativa entre o texto da lei e sua aplicabilidade (FRANCO, 1960). Isso se dava quase que exclusivamente pela instabilidade política mundial, que refletia no Direito Constitucional e da força normativa das constituições. Afonso Arinos de Melo Franco apresenta um quadro em que o liberalismo fracassou, mesmo sendo um modelo no qual as constituições eram facilmente aplicáveis, e o autoritarismo também tinha fracassado com a $2^{\circ}$ Guerra Mundial, deixando um cenário de pouca definição política e constitucional nos países do ocidente.

Somando-se a essa situação de mudança global, em que não se aceitava mais o desrespeito a um mínimo ético tolerável mundialmente, estabelecendo-se que particularidades culturais e individuais não poderiam superar valores humanos universais (SOUZA NETO; SARMENTO, 2012), as constituições que se seguiram passaram a ser cartas com conteúdo mais substancial e tiveram em comum o fortalecimento do papel dos tribunais constitucionais.

O presente estudo tem como objetivo analisar comparativamente a evolução do constitucionalismo e das constituições, inseridas nesse contexto histórico-político-jurídico acima mencionado, com foco no Brasil, para estabelecer a evolução do papel do Supremo 
Tribunal Federal Brasileiro tanto no período de instabilidade política no pós-guerra quanto na redemocratização que originou a Carta de 1988, analisando o substancialismo das constituições e a função efetiva da corte constitucional para a garantia dos direitos fundamentais nelas previstos.

Em um primeiro momento, analisaremos o contexto histórico-político-jurídico que se estabeleceu pós $2^{\mathrm{a}}$ Guerra Mundial para definir as influências sofridas pela Constituição de 1946, bem como o papel estabelecido para os três poderes e a função do Supremo Tribunal Federal no controle de constitucionalidade das leis. Em seguida, analisaremos o período da redemocratização e a Constituição de 1988, sua representação para o Estado Social no Brasil e, comparativamente, a forma do controle de constitucionalidade das leis e a evolução do papel do Supremo Tribunal Federal. Por fim, faremos a análise dessa crescente atuação da corte constitucional no contexto do neoconstitucionalismo e sua influência na democracia e separação de poderes.

\section{CONSTITUCIONALISMO PÓS $2^{\mathrm{a}}$ GUERRA MUNDIAL: DA CONSTITUIÇÃO LIBERAL À CONSTITUIÇÃO SOCIAL}

Para compreendermos a evolução das constituições e o papel do Estado em cada momento histórico que marcou essa evolução, é fundamental uma breve análise do constitucionalismo, desde o período antigo até a contemporaneidade, passando por dois momentos relevantes que originaram a constituição liberal e a constituição social.

No período antigo e medieval não se pode dizer que havia constituições como se observou na modernidade, porém alguns movimentos podem ser considerados como corresponder a um modelo de constitucionalismo que vigorava à época. Para Maurizio Fioravanti (2001), não é possível analisar as constituições antigas e medievais na perspectiva do que contemporaneamente se entende por constituição, devendo levar em consideração critérios temporais e culturais para estabelecer o que é a constituição antiga e o que é a constituição medieval. No período antigo, podemos exemplificar a politeia grega, que representava a tomada de decisões na ágora, em um modelo de democracia direta, mesmo que alguns habitantes estivessem excluídos (FIORAVANTI, 2001). O constitucionalismo, como entendemos 
contemporaneamente, no entanto, não se observava exatamente nesse período porque não havia, nesse contexto, a verificação dos elementos que o compõem.

Luis Roberto Barroso (2010, p. 32) define constitucionalismo como "limitação do poder e supremacia da lei”, indicando, assim, que o Estado estaria limitado pela lei dentro do fenômeno constitucional. Nesse mesmo sentido, Canotilho (2007, p. 51) nos fornece um conceito mais sofisticado: "constitucionalismo é a teoria (ou ideologia) que ergue o princípio do governo limitado indispensável à garantia dos direitos em dimensão estruturante da organização político-social". Maurizio Fioravanti também trata do conceito de constitucionalismo em sua obra, definindo-o como "el conjunto de doctrinas que aproximadamente a partir de la mitad del siglo XVII se han dedicado a recuperar en el horizonte de la constitución de los modernos el aspecto del limit y de la garantia"1. Em todos, o constitucionalismo erige com a finalidade precípua, se não única, de impedir que o soberano (o Estado) tenha poderes ilimitados e esteja acima da lei.

Após o período medieval, alguns pactos surgiram com estrutura mais próxima do que entendemos por constitucionalismo modernamente, sendo o mais famoso a Carta de João Sem Terra, em 1215, na Inglaterra, cujo objetivo foi assegurar que o Rei respeitasse direitos da nobreza inglesa. Esses documentos, não obstante sua relevância histórica e política, careciam de alguns requisitos para serem considerados constituições como modernamente se estabeleceu, como, exemplificativamente, a universalidade, uma vez que limitavam as ações do Rei para apenas um grupo exclusivo, sem garantir direitos para todos os cidadãos (SOUZA NETO; SARMENTO, 2012). Esse modelo é denominado constitucionalismo antigo (CANOTILHO, 2007) e foi contraposto pelo constitucionalismo moderno, que passou a vigorar aproximadamente no século XVIII.

\footnotetext{
1 Em tradução livre, "o conjunto de doutrinas que, aproximadamente a partir da metade do Século XVII, dedicaram-se a recuperar, no horizonte da constituição moderna, os aspectos do limite e da garantia”.
} 
Para prosseguirmos à análise do constitucionalismo, torna-se necessária uma desambiguação. O terma constitucionalismo moderno será empregado neste estudo para designar o movimento constitucional desde a origem da constituição liberal, e nesse aspecto é fundamental distinguir constitucionalismo - teoria, ideologia - de constituição - documento escrito que ordena sistematicamente o Estado (CANOTILHO, 2007). Temos então o constitucionalismo antigo, que remonta a períodos históricos nos quais o termo nem mesmo seria condizente com a estrutura dos Estados, utilizado academicamente para fins didáticos, e

o constitucionalismo moderno, que pode ser observado por volta do século XVIII e que engloba dois tipos de constituição, a liberal e a social, objetos de nossas análises nesse estudo.

O constitucionalis mo moderno surgiu em um período histórico que não comportava mais o Estado absolutista. Souza Neto e Daniel Sarmento (2012) elencam algumas condições favoráveis à superação do Absolutismo, como o pluralismo religioso europeu, que influenciaria na percepção de que o monarca havia sido designado por Deus; a ascensão burguesa, que se tornou uma classe em busca de poder político e direitos que possibilitassem o fortalecimento e o aumento de suas riquezas; e o Iluminismo.

O Estado moderno também contribuiu para o levante do capitalismo, buscando encerrar o pluralismo jurídico que vigorava com o feudalis mo (SOUZA NETO; SARMENTO, 2012). Considerando que cada feudo tinha suas próprias regras e sua própria moeda, o comércio entre eles era difícil e a unificação política e econômica favoreceu a expansão capitalista e a burguesia.

O Iluminismo influenciou a formação do Estado moderno ao estabelecer o homem como centro e fundar bases racionais para o governo de um estado. O indivíduo adquiriu destaque e, com isso, dissociou-se do coletivo e passou a importar tanto quanto, ou até mais do que o grupo. Nesse sentido, "o constitucionalismo moderno sustenta a limitação jurídica do poder do Estado em favor da liberdade individual" (SOUZA NETO; SARMENTO, 2012, p. 54). A relevância adquirida pelo indivíduo e sua razão elevaram o contrato (entre indivíduos) à máxima representação de sua liberdade, não devendo sofrer a interferência do Estado.

A constituição que se observa nesse período é denominada liberal ou liberal-burgue sa. Ela se sustentava em uma base de direitos negativos e limitação de interferência estatal nos 
direitos dos indivíduos. Como expressam Souza Neto e Daniel Sarmento (2012, p. 59), no modelo liberal "os direitos fundamentais eram concebidos como direitos negativos, que impunham apenas abstenções aos poderes políticos". Dessa forma, não havia expresso na constituição liberal direitos que o Estado deveria efetivar para o cidadão. Bastava que ele deixasse de interferir e impedir que os indivíduos agissem livremente, essa era a proposta fundamental do constitucionalismo liberal.

Considerando que o Estado absolutista era totalitário e não permitia a nenhum indivíd uo se relacionar livremente com outro, pois o rei ou príncipe interviriam sempre se entendesse necessário, além da falta de liberdade política e social, pois não havia representatividade ou direito de participação na vida pública, a abstenção estatal já se mostrava como grande evolução no tocante ao respeito de direitos generalizados, que não excluíssem nenhuma pessoa da sua esfera de proteção. A constituição liberal, no entanto, proporcionou severa crise social de desigualdade entre pessoas. A característica individualística dos direitos negativos não favorecia o desenvolvimento de políticas sociais - em verdade, elas não eram consideradas necessárias ou relevantes, e isso conduziu as relações pessoais a um abismo de diferenças, com os mais ricos se tornando cada vez mais ricos e os mais pobres mergulhados na pobreza absoluta e sem quaisquer condições de vida digna.

A ameaça de uma revolução proletária, que poderia romper com o estado liberal, desagradava às classes mais favorecidas economicamente. O temor de retorno a uma condição totalitária ou da implantação de um estado desconhecido fez com que direitos sociais, de natureza positiva, fossem implantados para sugerir a intervenção do estado na regulação de questões necessárias, como a relação de trabalho e a efetivação de políticas buscando a redução da pobreza. Como bem remonta Souza Neto e Daniel Sarmento (2012), já no final do Século XIX e início do Século XX, a degradação das condições sociais de trabalhadores, causada pelo capitalismo selvagem levado a cabo pela revolução industrial e pela liberdade extrema de contratar sem qualquer controle ou interferência estatal culminou em pressões das classes oprimidas e gerou temor de revoltas sociais que poderiam causar a ruptura total do modelo vigente.

O capitalismo sem controle causou, além de desigualdades sociais severas, prejuízo à livre concorrência. A crise de 1929 foi também um marco relevante, em termos econômicos, para justificar a intervenção estatal nas relações individuais. Sem essa intervenção não haveria 
como enfrentar a crise, mas a atuação do Estado não seria compatível com o modelo constitucional até então vigente, sendo imprescindível que ele fosse colocado de lado para dar lugar a outro, mais condizente com as necessidades do momento socio-político-econômico: o Estado Social.

\footnotetext{
No novo cenário, o estado incorpora funções ligadas à prestação de serviços públicos. No plano teórico, a sua atuação passa a ser justificada também pela necessidade de promoção da igualdade material, por meio de políticas públicas públicas redistributivas e fornecimento de prestações materiais para as camadas mais pobres da sociedade, em áreas como saúde, educação e previdência social (SOUZA NETO; SARMENTO, 2012, p. 61).
}

Dessa forma, o Estado Social tomou forma ainda antes do período histórico da $2^{\text {a }}$ Guerra Mundial, porém não apresentava, ainda, as características que assumiu em momento posterior a esse, conforme veremos a seguir.

\section{O SUBSTANCIALISMO DAS CONSTITUIÇÕES E A EFETIVAÇÃO DE DIREITOS FUNDAMENTAIS PELO ESTADO BRASILEIRO}

A $2^{\text {a }}$ Guerra Mundial causou profundas mudanças de nível global, e influenciou também o constitucionalismo moderno e as constituições liberais, que ocupavam-se apenas da forma político-estatal e da proteção ao indivíduo, por meio dos direitos negativos, como visto acima. Isso porque a ideologia surgida com o Estado Liberal não foi capaz de proteger os cidadãos de uma nação de regimes totalitários que se legitimaram em suas cartas constitucionais para cometer o que posteriormente foram considerados crimes contra a Humanidade.

Como exemplo, os regimes nazista e fascista que culminaram com a própria $2^{\mathrm{a}}$ Guerra, ambos supostamente legítimos e ancorados em normas legítimas elaboradas pelo Estado para sustentar as pretensões de seus governantes ${ }^{2}$. Com a derrota desses estados totalitários e a percepção mundial de que as atrocidades nazistas eram crimes que um estado constitucional não deveria cometer, as constituições passaram por uma revisitação ideológica que viria a superar a perspectiva de que bastaria o Estado abster-se de interferir nos direitos e liberdades do cidadão - ele teria que fazer mais, teria que assegurar, positivamente, que os cidadãos gozassem de determinados direitos e prerrogativas. 
É importante, para o momento, destacar os ensinamentos de José Luis Fiori (1997) no sentido de que o que se realmente pode chamar de Estado Social teve como marco inicial a o Plano Beveridge, que institui o National Health Service Care, de natureza universal, geral e publicamente financiado, em 1946. Ele menciona quatro pilastras para identificação do Estado Social, interessando-nos a terceira, que se relaciona a movimentos ideológicos que surgiram

depois da $2^{\text {a }}$ Guerra Mundial, atribuindo força significativa ao "clima" de solidariedade nacional que instalou-se logo depois da guerra dentro dos países vencedores e vencidos, e, logo depois, pela solidariedade supranacional gerada pelo novo quadro geopolítico. A nova situação ao bipolarizar ideologicamente os conflitos mundiais entre duas propostas excludentes de organização econômica e social, criaram os estímulos ou receios necessários para consolidar as convicções "socialmente orientadas" de todos os governos, aí incluídos os conservadores os democrata-cristãos e os liberais (FIORI, 1997, p. 134).

Assim, observa-se que o movimento do Estado Social, associado ao constitucionalismo moderno, efetivou-se após o fim da $2^{\mathrm{a}}$ Guerra Mundial e consolidou o papel do Estado como atuante para a garantia de direitos aos cidadãos, atribuindo-lhe papel mais significativo do que a abstenção de uma intervenção. O constitucionalismo passou, então, por uma transição que o levou de um modelo estritamente liberal, garantidor de direitos fundamentais para os cidadãos porém sem interferência estatal ou garantia de universalidade desses direitos, para o modelo social, que demandava a intervenção do poder público para a efetivação dos direitos positivados e que esses direitos fossem genéricos, garantidos a todos, sem discriminações de classes, estamentos, raça, etc. Nas palavras de Deborah Moretti e Yvete da Costa (2016, p. 115), “[...] a meta central das constituições modernas pode ser resumida na promoção do bem-estar do ser humano, cujo ponto de partida está em assegurar as condições de exercício de sua própria dignidade, que inclui, além da proteção aos direitos individuais, sua efetivação."

\footnotetext{
${ }^{2}$ Nesse sentido, observamos a crítica de Gustav Radbruch, que atribuiu ao Positivismo Jurídico responsabilidade pelas mazelas humanas deflagradas pelo Nazismo alemão, que se justificou em leis formalmente válidas dentro de um estado de direito para o cometimento de atrocidades contra grupos es pecíficos de pessoas, com ênfase nos judeus.
} 
Essa crise geral do constitucionalismo, garantido o fracasso do modelo liberal, teve uma consequência grave apontada por Afonso Arinos (1960): o esvaziamento da força das constituicões, que passaram a ser vistas como meras cartas informativas, sem valor normativo direto e significativo. O fracasso do autoritaris mo, refletido pela vitória dos aliados na $2^{\mathrm{a}}$ Guerra Mundial, gerou um cenário de instabilidade constitucional que prejudicou a efetividade das constituições. A situação também é pontuada por Souza Neto e Daniel Sarmento (2012, p. 62) ao afirmarem que "nem sempre o Estado Social pautou-se pelo respeito à lógica do Estado de Direito. Em diversos países, a crise do liberalismo levou o ideário constitucionalista a ser visto como relíquia de museu".

Tanto que muitas constituições elaboradas nesse período não eram exatamente eficientes ou foram eficazes para garantir tudo que se comprometiam, como é o próprio caso do Brasil. Vindo de um governo autoritário, a retomada democrática de 1946 deu origem a uma constituição de pouca expressão substancial, que não foi efetiva nem capaz de sustentar a própria democracia por ela instalada (FRANCO, 1958). Isso mostra que a transição do Estado

Liberal para o Estado Social não foi imediata, mas gradativa.

A mudança paradigmática aconteceu de formas diferentes em diferentes países. Nos Estados Unidos, tradicionalmente um país common law com uma constituição enxuta e objetiva, não houve, no texto constitucional, incorporação positiva de direitos fundamentais ou determinação de que o Estado atuasse para a sua efetivação, ou interferisse na vida privada dos cidadãos (SOUZA NETO; SARMENTO, 2012). A constituição americana não sofreu alterações significativas em seu texto, mas em sua interpretação, como explica Luis Roberto Barroso (2010, p. 18):

\footnotetext{
É certo que o sistema jurídico americano, fundado na tradição do common law, dá aos tribunais um amplo poder de criação e adaptação do Direito e que, por is so mes mo, a Constituição tem hoje um sentido e um alcance que se distanciam de sua concepção original. Em diversas matérias é possível afirmar que o direito constitucional mudou substancialmente sem que para isso se operasse uma alteração do texto originário. Mas não deve se minimizar a circunstância de que a Constituição teve a plasticidade necessária para se adaptar a novas realidades.
}

Na maioria dos países, no entanto, a mudança foi estrutural e incorporada nos textos constitucionais. As primeiras constituições que trouxeram preceitos do Estado Social em seu bojo foram a Constituição do México, de 1917, e a Constituição de Weimar (Alemanha) de 
1919 (MORETTI; COSTA, 2016), apesar de entendermos que elas não instituiram Estados Sociais nem consolidaram o constitucionalismo social. No Brasil, a Constituição de 1946 ainda se mostrou uma carta quase que exclusivamente política, objetivando estruturar o Estado e sem preocupação com a concreta efetivação de direitos fundamentais. Em verdade, os direitos individuais vieram apresentados apenas a partir do artigo 141, com uma proposta bem próxima dos direitos negativos do Estado Liberal. Porém, em capítulos anteriores, assegura direitos como trabalho digno, educação e saúde para todo cidadão, incorporando a proposta do Estado Social. Não havia, no entanto, previsão de atuação forte do Estado para a efetivação desses direitos.

Há pouca discussão sobre o papel atuante do Estado brasileiro na Constituição de 1946 porque, em em verdade, ele foi fictício. Essa constituição também fracassou em impedir que o país mergulhasse novamente em um período de autoritarismo com o golpe militar de 1964. Mesmo que a Europa caminhasse em direção diversa, da democracia e do Welfare State (o Estado Social), o Brasil vivenciou um período de aproximadamente vinte anos de ditadura governamental sem o reconhecimento constitucional dos direitos e garantias negativos do próprio ideário liberal-burguês. Uma das mais retumbantes justificativas desse regime autoritário foi impedir que o comunismo, em ascensão na então União Soviética, fosse implantado no Brasil. Gradualmente, em um processo iniciado por Ernesto Geisel e consumado por João Figueiredo, a democracia foi sendo reimplantada no país (BARROSO, xxx). Os movimentos ditatoriais perderam sua força inicial e, em 1984, as ruas foram tomadas por cidadãos desejando eleições diretas para os cargos políticos nacionais.

Com a eleição da chapa de oposição, em 1985, e a convocação de assembleia constituinte para revisão da Constituição brasileira, que havia sido mutilada e desmembrada durante o período de governo militar, o movimento observado no Brasil foi similar àquele observado na Europa logo ao final da $2^{\circ}$ Guerra Mundial: a necessidade de se implantare $\mathrm{m}$ medidas suficientes para impedir um novo golpe à democracia. A derrota do nazismo fez surgir reflexão maior sobre direitos humanos e fundamentais e sua garantia pelo Estado, e essa reflexão repetiu-se no país quando ele viu-se liberto do autoritarismo.

A Constituição de 1988 implantou o modelo de Estado Social no Brasil, mesmo que tardiamente, em se considerando alguns países europeus. Foi elaborada durante 18 meses e denominada "Constituição cidadã". Luis Roberto Barroso (2008, p. 13) enfatiza que "a 
Constituição de 1988 é o símbolo maior de uma história de sucesso: a transição de um Estado autoritário, intolerante e muitas vezes violento para um Estado democrático de direito". Nesse sentido, ressalta que a carta instituída em 1988 conseguiu cumprir o papel político que outras não tiveram sucesso, como garantir a democracia (eleições diretas, voto universal, representatividade, etc) e o cumprimento dos mandatos dos chefes eleitos para o Executivo.

Retomando a análise do constitucionalismo pós $2^{\text {a }}$ Guerra Mundial a níveis globais, a alteração paradigmática ocorrida nesse período histórico atingiu a forma em que as constituiçõ es eram consideradas. Havia predomínio do modelo francês, que definia uma constituição como documento político para nortear especificamente o Poder Legislativo, sem potencialidade de gerar direitos diretos aos cidadãos ou de ser plenamente "exercida" pelo Poder Executivo (BARROSO, 2005). Essa constituição também não podia servir de base para o Poder Judiciário em análise a casos concretos, ou seja, não podia ser invocada como fundamento jurídico. Tratava-se de uma premissa democrática, já que era o parlamento eleito para representar a nação com suas decisões, não o Judiciário (SOUZA NETO; SARMENTO,

2012).

Foi exatamente a $2^{\mathrm{a}}$ Guerra Mundial que deu a dimensão da aparente ineficiência desse modelo, que não impediu as graves violações cometidas pelo nazismo. Sem especial força coercitiva e aplicabilidade concreta, nenhuma constituição seria suficiente para evitar que outras violações surgissem e que os poderes usurpassem de suas funções. A solução encontrada para isso, constitucionalmente, foi reforçar a gama de direitos e possibilitar ao Judiciário um maior controle de constitucionalidade das normas que, até então, era praticamente inexistente como regra geral. À constituição originada desse movimento, nomeou-se substancialista, por garantir direitos materializáveis ao invés de apenas formais.

Após derrota do totalitarismo, o movimento constitucional seguiu no sentido não apenas de transformar as constituições em substanciais, repletas de normas concretas e exigíveis diretamente, mas de implementar jurisdições constitucionais. Nas palavras de Luis Roberto Barroso (2005, p. 05),

Uma das grandes mudanças de paradigma ocorridas ao longo do século XX foi a atribuição à norma constitucional do status de norma jurídica. Superou-se, assim, o modelo que vigorou na Europa até meados do século passado, no qual a Constituição era vista como um documento essencialmente político, um convite à atuação dos Poderes Públicos. A concretização de suas propostas ficava 
invariavelmente condicionada à liberdade de conformação do legislador ou à discricionariedade do administrador. Ao Judiciário não se reconhecia qualquer papel relevante na realização do conteúdo da Constituição.

Desde então, o constitucionalismo moderno evoluiu para o que se denomina neoconstitucionalismo, prestigiando a intervenção do Poder Judiciário para a efetivação dos direitos inseridos nas constituições do pós $2^{\mathrm{a}}$ Guerra Mundial. Trata-se de um movimento sincronizado e justificado em razão da ressignificação da própria constituição. O modelo liberal entrou em colapso porque a previsão exclusiva de direitos negativos e os obstáculos à intervenção estatal na vida social não era suficiente. Paulatinamente, as constituições liberais foram sendo substituídas por cartas mais robustas e que previam não apenas direitos negativos, mas a atuação concreta do Estado para a efetivação de direitos fundamentais e sua intervenção na vida social. Para que isso funcionasse, não era mais possível se tomar a constituição como mera carta política a nortear o parlamento e garantir um estado de direito. As constituições tinham que ser efetivas, de materialização possível, invocáveis sempre que necessário proteger indivíduos do próprio Estado e garantir a eles os seus princípios norteadores.

\section{ATIVISMO JUDICIAL E A EVOLUÇÃO DO PAPEL SUPREMO TRIBUNAL FEDERAL: A BUSCA DE UMA CONSTITUIÇÃO EFETIVA}

Até o advento das constituições substancialistas do Estado Social, praticamente não se falava em controle de constitucionalidade das leis. Esse é um fenômeno que passou a incorporar as cartas constitucionais basicamente no constitucionalismo pós $2^{\mathrm{a}}$ Guerra Mundial e que acompanhou o fenômeno do Estado Social, com a proposta de intervenção concreta e frequente do Estado nas relações sociais e até mesmo individuais. Os países adotaram modelos para controlar a constitucionalidade das leis baseado na criação de Tribunais Constitucionais, e o Poder Judiciário assumiu papel relevante como guardião dos direitos que estavam postos nas constituições.

A garantia desses direitos se relacionava com a própria ideia de democracia (DEMARCHI; CADEMARTORI, 2010). A constituição liberal tinha como premissa garantir liberdade do indivíduo em relação ao Estado, e o modelo francês ditava que apenas questões 
políticas e referentes ao estado (democrático) de direito pudessem ser tratadas pela norma fundamental, não devendo o Judiciário imiscuir-se em controle de constitucionalidade severo pois isso representaria risco à democracia. Afinal, os representantes do povo, eleitos pelo povo, compunham parlamento e Executivo, devendo estes interpretar a constituição conforme a vontade do povo que representavam.

A incorporação de direitos substanciais nas constituições, no entanto, como já visto, clamava por mais atuação para que esses direitos não fossem violados nem mesmo pelos representantes do povo, pois isso se viu possível após a $2^{\mathrm{a}}$ Guerra Mundial. Assim, democracia e efetivação de direitos fundamentais devem ser indissociáveis em um estado constitucional de direito. Outro entendimento poderia novamente legitimar ou corroborar atos como os do nazismo Alemão, sem que a corte constitucional pudesse atuar de forma a impedir a violação de direitos fundamentais.

O Brasil demorou mais do que os países europeus para adentrar a onda do Estado Social. A Constituição de 1946, mesmo tendo sido elaborada no pós-guerra, não seguiu exatamente a linha das constituições europeias que foram promulgadas em datas próximas, e não possuía um controle sofisticado de constitucionalidade, exercendo o Supremo Tribunal Federal papel praticamente figurativo (FRANCO, 1960). A pouca força da carta de 1946, somada à apatia do Executivo e à incapacidade do Judiciário em fazer cumprir a constituição provavelmente levaram o país a viver uma segunda experiência autoritária, dessa vez com o golpe de 1964 em que as Forças Armadas assumiram o governo federal.

A partir de então, foram vinte anos de autoritarismo sem que uma constituição garantista, nem liberal, nem social, estivesse vigente no Brasil. Não havia direitos fundamentais negativos que o Estado deveria respeitar, como liberdade, privacidade ou confidencialidade. Os documentos constitucionais que seguiram à Constituição de 1946 tratavam de um estado de direito, mas ele não era democrático e os poderes não eram independentes entre si. Foi apenas em 1985 que o Brasil iniciou sua caminhada para a promulgação de uma constituição social, que foi a carta de 1988.

Em texto elaborado para festejar os vinte anos da Constituição de 1988, Luis Roberto Barroso (2008) enaltece o documento que consolidou o estado democrático Brasileiro por ter conseguido manter a democracia e, positivamente, por fortalecer o Poder Judiciário. Nesse sentido, a carta de 1988 assemelhou-se significativamente com as outras constituições sociais já 
em vigor no mundo, pois também previa um papel relevante da corte constitucional na efetivação dos direitos fundamentais que a própria constituição assegurava. O Supremo Tribunal Federal já existia, porém sua atuação era formalística e não desempenhava um papel importante como o que the assegurou a Constituição de 1988. Nas palavras de Luis Roberto Barroso (2008, pp. 211-212)

\begin{abstract}
A ascensão do Poder Judiciário se deve, em primeiro lugar, à reconstitucionalização do país: recuperadas as liberdades democráticas e as garantias da magistratura, juízes e tribunais deixaram de ser um departamento técnico especializado e passaram a desempenhar um papel político, dividindo espaço como Legislativo e o Executivo.
\end{abstract}

Esse foi um movimento significativo observado no $2^{\circ}$ Pós-guerra, a compreensão de que o Poder Judiciário deveria colocar-se atuante para evitar que Executivo e Legislativo desvirtuassem as constituições, ou deixassem de aplicá-las. A interferência judicial no espectro democrático, entregando às cortes constitucionais papel político, acompanhou a mudança da própria teoria do constitucionalismo e o surgimento do que se denomina neoconstitucionalismo.

Para Deborah Moretti e Yvete da Costa (2016), como o Estado Brasile iro reiteradamente se recusa a cumprir os programas e planos para a efetivação desses direitos fundamentais, a atuação do Judiciário se torna relevante e fundamental para a realização adequado da Constituição de 1988. Nesse contexto está o que se denomina ativismo judicial ou judicialização da política (BARROSO, 2012 e MORETTI; COSTA, 2016), ou seja, o fato que "questões relevantes do ponto de vista político, social ou moral estão sendo decididas, em caráter final, pelo Poder Judiciário" (BARROSO, 2012, p. 05). A transferência de atuação no sentido de efetivar as políticas públicas que visam à implementação de direitos e garantias fundamentais para o cidadão, dos poderes democráticos (Executivo e Legislativo) para o Judiciário vem marcando os Estados Sociais desde o Século XX, pautada basicamente no reconhecimento da importância desse poder (Judiciário) para o cumprimento da Constituição e na crise de legitimidade dos poderes democráticos, que causou uma desilusão popular com a atividade de seus representantes (BARROSO, 2012).

Luis Roberto Barroso (2012) chega a afirmar que os atores políticos até mesmo preferem que seja o Judiciário a tomar decisões em questões mais complexas. Afinal, sendo composto por membros não eleitos pelo voto popular, estaria menos comprometido em "satisfazer" os 
eleitores e, portanto, poderia ser capaz de aplicar e interpretar a lei com objetividade e racionalidade. Nesse sentido também observam Souza Neto e Daniel Sarmento ao explicitare m corrente ideológica que defende a judicialização da constituição. Assim "a jurisdição constitucional é o espaço por excelência da afirmação da Constituição, onde os temas controvertidos são equacionados com base no Direito e não em preferências ideológicas, interesses ou compromissos políticos" (SOUZA NETO; SARMENTO, 2012, p.191).

O ativismo judicial não repercute exclusivamente na esfera constitucional, mas torna- se deveras mais relevante ao destacar o Supremo Tribunal Federal, antes um órgão destituído de importância no cenário político-jurídico nacional e, posteriormente, alçado àquele que "dá a última palavra", que interpreta e norteia a aplicação da carta constitucional. Em um Estado Democrático de Direito, apresenta-se curioso que o poder a "dizer o que a lei quer dizer" seja o único que não possui representatividade, ou seja, que não é formado por membros democraticamente escolhidos para atuar em nome do povo.

Por certo, a atuação do Judiciário para cumprimento da norma constitucional só se dá quando ela, efetivamente, deixa de ser aplicada de forma a garantir os direitos fundamentais previstos em seu texto. Sem conflito de aplicabilidade, não há justificativa ou interesse na interferência judicial na questão. No entanto, a ineficiência dos poderes Executivo e Legislativo em interpretar e efetivar a constituição tem levado à atuação cada vez mais incisiva do Supremo Tribunal Federal, que sub-rogou para si a função de guardião da constituição e, consequentemente, de garantir a implementação dos direitos fundamentais nela previstos. Assim,

\footnotetext{
O magistrado, exercitando atividade jurisdicional em um Estado do bem-estar social, deve redimensionar o seu foco de análise, investigando o fundamento de todos os atos estatais a partir dos objetivos fundamentais inseridos na Constituição da República. A Constituição deverá receber uma leitura finalística, de tal forma que o art. $2^{\circ}$, matriz do princípio da separação entre os poderes, deverá ser obrigatoriamente revisitado (MORETTI; COSTA, 2016, p. 123).
}

Esse é o cenário que se mostra, no Século XXI, em relação à Constituição Brasileira de 1988: um texto amplamente garantista, inspirado no constitucionalismo pós $2^{\text {a }}$ Guerra Mundial, repleto de direitos fundamentais individuais e sociais que exigem atuação forte do Estado para sua implementação, além da revisitação do papel do Supremo Tribunal Federal, 
que deixou de ser um poder apático e de atuação quase formalista para efetivamente defender a própria constituição de possíveis ataques, sustentando, assim, o Estado Democrático de Direito por ela instituído. Nesse panorama de evolução, tanto do conteúdo das constituições, que passaram de documentos formais para substanciais, também operou uma evolução do papel do Poder Judiciário em relação a essas constituições.

\section{CENÁRIO ATUAL E CONCLUSÕES}

O cenário atual é de fortalecimento progressivo do Supremo Tribunal Federal. A corte constitucional Brasileira vem tomando decisões cada vez mais políticas e interferentes nos poderes Executivo e Legislativo, ultrapassando significativamente o simples controle de constitucionalidade das leis. Em verdade, o Supremo Tribunal Federal interpreta até mesmo a Constituição conforme a Constituição, como se deu no recente julgamento do Habeas Corpus 126.292 em que, por maioria, a corte determinou que a prisão dos réus em ação penal pode acontecer após a decisão de segunda instância, mesmo pendente recurso para os tribunais superiores, ressignificando o disposto no inciso LVII do artigo $5^{\circ}$ da Constituição de 1988 .

Não apenas decisões políticas povoam o repertório decisório do Supremo Tribunal Federal, que determina a realização impositiva de políticas públicas e outras atividades pelos poderes Executivo e Legislativo, em nome da garantia dos direitos fundamentais do cidadão Brasileiro. Assim foi na decisão do Recurso Extraordinário 592.581 ao determinar que o princípio da reserva do possível não pode ser invocado pelo Executivo para deixar de cumprir determinação da corte constitucional - que significaria determinação da própria Carta de 1988. Nesse mesmo sentido, o julgamento do Agravo de Instrumento 813.590, de relatoria do Ministro Dias Tóffoli, que reforma decisão do Tribunal de Justiça de Minas Gerais para sustentar a legitimidade do Judiciário em interferir na adoção e regulação de políticas públicas pelo Executivo.

A interferência do Judiciário no Executivo já é pauta frequente também em demandas que pleiteiam o fornecimento de medicamentos de alto custo e a realização de procedimento s não custeados pelo Sistema Único de Saúde, ou que não estejam sendo fornecidos e realizados em prazo razoável, conforme critérios definidos pelo usuário ou pelo próprio Judiciário.

Eventuais críticas quanto a essa proatividade do Supremo Tribunal Federal são 
elididas pelo próprio tribunal, que argumenta ser papel do Poder Judiciário fiscalizar os demais poderes e efetivar os direitos fundamentais previstos na Constituição de 1988. Em momentos anteriores da história Brasileira tais argumentos não se sustentariam, já que as cartas constitucionais não elencavam farta gama de direitos a serem efetivados pelo Estado. Tais cartas nem mesmo atribuíam papel relevante ao Judiciário. Porém, após a Constituição de 1988 e a apatia Executiva e Legislativa em garantir o rol de direitos nela previstos para todos os cidadãos Brasileiros, a intervenção do Supremo Tribunal Federal se justificaria para que o texto constitucional não representasse mera formalidade.

Não obstante estarem esses números em queda há alguns anos, os dados oficiais do Governo indicam que 7 milhões de pessoas passam fome no Brasil (EXAME, 2014). Dessa mesma forma, 2,5 milhões de pessoas estavam desempregadas em 2015 (EXAME, 2016). A população carcerária Brasileira chegou a 715 mil detentos, segundo o Conselho Nacional de Justiça, e é a quarta maior do mundo (AGÊNCIA BRASIL, 2014). Mesmo que o cenário tenha melhorado em relação à fome e à miséria, ele paradoxalmente não melhorou quanto ao desemprego em período de crise econômica. Vinte e oito anos depois da promulgação da primeira constituição substancialista do Brasil, responsável pela instalação do Estado de BemEstar Social nacional, alinhada com a proposta do constitucionalismo pós $2^{\text {a }}$ Guerra Mundial e com os direitos humanos universalizados, o Estado ainda não conseguiu garantir que essa parte materialista da Carta de 1988 seja efetivada.

Não podemos desconsiderar o papel que a Constituição de 1988 teve para a democracia, pois a Constituição de 1946 não foi forte o suficiente para evitar o golpe militar em 1964. Esse retorno ao umbral do autoritarismo aconteceu porque, em 1946, tivemos uma constituição meramente formalista e que relegou o Poder Judiciário a um papel de enfeite (FRANCO, 1960). Essa conclusão releva a importância da atuação do Judiciário tanto para a aplicação da constituição quanto para a manutenção da própria democracia nacional.

Considerando o papel do Estado Social e a importância conferida aos direitos fundamentais universalizados, aqueles que nenhum Estado pode deixar de implementar para seus cidadãos, não se deve tolerar que os poderes de um Estado Democrático de Direito deixem de aplicar a norma constitucional, que positiva tais direitos fundamentais, por conveniência ou simples inércia. Sempre que o Legislativo deixa de observar sua função de elaborar leis 
representando o povo que o elegeu, e o Executivo deixa de realizar políticas públicas essenciais para a efetivação daqueles direitos previstos na norma constitucional, colocam o Estado e a própria democracia em risco.

Por menos representativo que seja o Supremo Tribunal Federal em razão da forma de escolha de seus membros, ele é o órgão escolhido pela própria Constituição de 1988 para garantir o seu cumprimento.

\section{REFERÊNCIAS}

AGÊNCIA BRASIL. População carcerária passa de 715 mil, diz CNJ. Disponível em http//agenciabrasil.ebc.com.br/direitos-humanos/noticia/2014-06/populacao-carceraria-passade-700-mil-e-deixa-brasil-em-3deg-no, acesso em 09 mar 2016.

BARROSO, Luis Roberto. Neoconstitucionalismo e constitucionalização do direito: o triunfo tardio do direito constitucional no Brasil. Revista de Direito Administrativo da FGV [online]. Rio de Janeiro, 240, Abr/jun, 2005. pp. 1-42.

. Vinte anos da constituição brasileira de 1988: o estado a que chegamos. Cadernos da Escola de Direito - UNIBRASIL. V. 1, n. 8, 2008.

Constituição, democracia e supremacia judicial: direito e política no Brasil contemporâneo. Revista da Faculdade de Direito da UERJ [online]. V. 2, n. 21, jan/jun 2012.

BRASIL. Constituição dos Estados Unidos do Brasil de 18 de setembro de 1946.

Disponível em http $/ / w w w . p l a n a l t o . g o v . b r / c c i v i l \_03 / C o n s t i t u i c a o / C o n s t i t u i c a o 46 . h t m$, acesso em 14 nov 2015.

. Constituição da República Federativa de 1988. Disponível em http://

www.planalto.gov.br/ccivil_03/Constituicao/Constituicao.htm, acesso em 14 nov 2015.

DEMARCHI, Clóvis; CADEMARTORI, Daniela Mesquita Leutchuk de. Do constitucionalismo ao neoconstitucionalismo. Revista USCS - Direito. Ano XI, n. 18, jan/jun 2010.

EXAME. Em 1 ano, 2,5 milhões entram na fila do desemprego, diz PNAD. Disponível em http//exame.abril.com.br/economia/noticias/em-1-ano-2-5-milhoes-entram-na-fila-dodesemprego-diz-pnad, acesso em 05 mar 2016. 
. Mais de 7 milhões de pessoas passam fome no Brasil. Disponível em http:// exame.abril.com.br/brasil/noticias/cai-o-numero-de-brasileiros-sem-dinheiro-para-comprarcomida, acesso em 05 mar 2016.

FIORAVANTI, Maurizio. Constitución. De la antigüedad a nuestros dias. Madri: Trotta, 2001.

FIORI, José Luis. Estado de Bem Estar Social: Padrões e crises. PHYSIS - Revista de Saúde Coletiva 7(2). Rio de Janeiro, 1997.

FRANCO, Afonso Arinos de Melo. Curso de Direito Constitucional Brasileiro. Vol. II. Rio de Janeiro: Forense, 1960.

MORETTI, Deborah Aline Antonucci; COSTA, Yvete Flávio da. A importância do ativismo judicial na implementação dos direitos sociais não implementados pelo poder público.

Revista Direitos e Garantias Fundamentais, v. 17, n. 1. Vitória: FDV, jan/jun 2016, pp. 111-134.

RADBRUCH, Gustav. Five minutes of legal phylosophy. Oxford Legal Studies, v. 26, n. 1, 2006. pp. 13-15.

SOUZA NETO, Cláudio Pereira; SARMENTO, Daniel. Direito Constitucional: Teoria, história e métodos de trabalho [e-pub]. Belo Horizonte: Ed. Fórum, 2012. 